\title{
Radiological and forensic veterinary analysis of gunshot cases in eastern Poland
}

\author{
PIOTR LISTOS, RENATA KOMSTA*, WOJCIECH ŁOPUSZYŃSKI, \\ MAGDALENA GRYZIŃSKA**, GRZEGORZ TERESIŃSKI***, WOJCIECH CHAGOWSKI***, \\ GRZEGORZ BUSZEWICZ***, MAŁGORZATA DYLEWSKA**
}

\author{
Department of Pathological Anatomy, *Department and Clinic of Animal Surgery, Faculty of Veterinary Medicine, \\ University of Life Sciences, Głęboka 30, 20-033 Lublin, Poland \\ **Department of Biological Basis of Animal Production, Faculty of Biology and Animal Breeding, \\ University of Life Sciences, Akademicka 13, 20-950 Lublin, Poland \\ ***Department of Forensic Medicine, Second Faculty of Medicine with English Language Division, \\ Medical University of Lublin, Ceramiczna 1, 20-150 Lublin, Poland
}

\section{Listos P., Komsta R., Łopuszyński W., Gryzińska M., Teresiński G., Chagowski W., Buszewicz G., Dylewska M. \\ Radiological and forensic veterinary analysis of gunshot cases in eastern Poland}

\section{Summary}

A widespread availability of firearms makes animals the victims of both intentional and accidental shootings by man. In Poland, statistical surveys on gunshot cases in animals are not carried out. The present authors attempt to assess the frequency and character of gunshot injuries in animals on the basis of their observations from 2000-2009, taking into account changes in the law regulating the availability of firearms. The material involved 171 study protocols of patients whose radiological evaluation revealed the presence of bullets. The analysis covered different species of animals, taking into account the number of fatal and nonfatal injuries. Besides, gunshot wounds were classified according to their direct effect on the animals' clinical status. During the radiographic assessment, the type of ammunition was also evaluated. The majority of gunshot victims were dogs $(\mathbf{7 8 . 3 6 \%})$, followed by cats $(\mathbf{1 5 . 2 0 \%})$, hares $(2.34 \%)$ and roe deer $(1.17 \%)$. The study also revealed the presence of bullets in the bodies of birds $(2.92 \%)$ (one great egret, one golden eagle, one buzzard, one raven and one jackdaw). Additionally, the animals' medical history was obtained from the owners (especially of dogs and cats) to determine whether the owners were aware of gunshot wounds in their pets. The amendment of the general provisions regulating the availability of firearms has affected the character of gunshot injuries and the number of victims.

Keywords: gunshot animal, forensic veterinary, radiological evaluation of animal

The general availability of firearms underlies the fact that animals become victims of gunshot wounds, resulting from both intentional and accidental activities of man $(17,24,26,27,30)$. This fact finds a direct reflection in the growing number of forensic examinations carried out by veterinarians as investigators or forensic experts.

No statistical studies on the number of gunshot animals have yet been undertaken in Poland, while the available literature suggests that the number of shootings of people has been growing steadily $(5,14,22$, $31)$. According to the Polish law in force since January 1,2004 , adult persons may possess air guns with both smooth-bore and rifled barrels and with bullet energy of less than $17 \mathrm{~J}$ (11).
$\mathrm{X}$-ray examination is a commonly recognised method in forensic medicine, used, among others, to identify corpses and to detect contrasting foreign bodies in tissues and organs. It is used in all cases in which the cause of the victim's death is unknown or when the degree of body degradation makes autopsy a serious challenge $(2,19,23)$. Similarly, in forensic veterinary medicine, radiological study is a basic, as well as obligatory, examination when gunshot is suspected. The examination is performed for a judicial-veterinary evaluation of both dead and wounded animals $(22,24,27)$.

On the basis of the relatively small number of Polish reports of gunshot injuries to animals, the authors evaluated the incidence and character of gunshot 
injuries in animals by analysing the radiological cases diagnosed during the years 2000-2009, including judicial-veterinary evaluations of gunshot animals. The results of the analysis were referred to changes in the common law, which controls the availability of firearms in Poland.

\section{Material and methods}

The material of the study consisted of patient case records from the Laboratory of Radiology and Ultrasound at the University of Life Sciences in Lublin. The cases selected concerned patients in which $\mathrm{x}$-ray examinations performed during the period of 2000-2009 revealed the presence of a bullet (complete or its fragment). The analysis was based on the radiograms of all patients examined during that period, including the radiological documentation of judicial-veterinary evaluations of the gunshot animals. Various animal species were included in the analysis, which concerned the effects of injuries on the clinical status of the animal and the number of deadly shots and intravital wounds. In addition, the type of ammunition used and the period before or after the amendment of the law were taken into account.

The animals with a radiologically identified bullet or its fragment were divided into two groups: group A included subjects examined during the years 2000-2003, i.e., before the amendment of the law, whereas group B consisted of animals examined from 2004 to 2009 , i.e. after the amendment.

Additionally, on the basis of data from patient case records for dogs and cats, an attempt was made to determine whether their owners had been aware of gunshot injuries in their pets.

The results of the study were analysed statistically by means of the Statistica 9.0 software package. Since some of the data were qualitative in character, the non-parametric Pearson's $\chi^{2}$ test for uniformity was applied (the minimum level of significance was set at a $\mathrm{P}$ value $<0.05$ ).

\section{Results and discussion}

The analysis covered radiograms of a total of 21,309 patients. Metallic foreign bodies, being either bullet fragments or complete bullets, were found in 171 animals, which made up $0.80 \%$ of all animals examined during the period in question. The majority of gunshot victims were dogs $-134(78.36 \%)$, followed by cats -26 $(15.20 \%)$, hares $-4(2.34 \%)$ and roe deer $-2(1.17 \%)$. The study also revealed the presence of bullets in 5 birds $(2.92 \%)$ (one great egret, one golden eagle, one buzzard, one raven and one jackdaw).

In $95(0.45 \%)$ of all animals examined and in 55.6\% of animals with a confirmed metallic object in their body, the bullet or its fragment demonstrated on the radiogram had no significant effect on the animal's health status, and the bullet was accidentally revealed during radiographic studies. In the other 76 animals $(0.36 \%$ of all animals examined and $44.4 \%$ of wounded patients), gunshots led either to death or to injury requiring medical intervention. That group of animals was the primary material for the analyses performed.

The percentage of gunshot wounds negatively affecting the clinical status of the animals examined

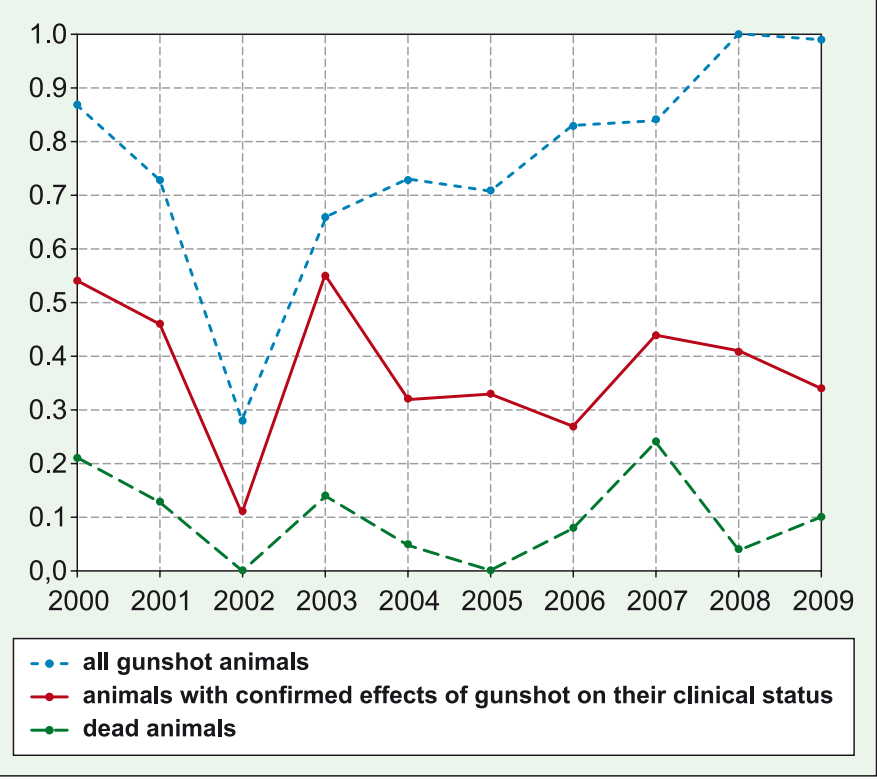

Fig. 1. The incidence (\%) of gunshot wounds in animals examined in subsequent years

in particular years varied from $0.11 \%$ to $0.54 \%$, while shootings of animals were most frequent in 2000, 2003 and 2007 (Fig. 1). The percentage of shots with fatal results varied during particular years (waved character) in a three-year cycle $(2002,2005,2008)$, and the highest number of fatal cases (6) were recorded in 2007. No correlations were found between the shootings recorded and the season of the year.

In the period before the law amendment (group A), the number of gunshot animals with confirmed effects on their clinical status was $27(0.37 \%)$ out of 7,392 animals studied during that period of time. After the law amendment (group B), the number of shot animals with consequences for their clinical status amounted to $27(0.37 \%)$ out of 13.917 animals studied (Fig. 2$)$.

In group A, 9 animals $(0.12 \%$ of all animals studied during that time) were killed, which made up 33.3\% of all animals in that group shot with confirmed effects on their clinical status. The animals most frequently wounded during that period were dogs $-22(81.48 \%)$, including 6 with fatal injuries, followed by cats -3 $(11.11 \%)$, including one death case, one bird (dead) and one hare (dead) (Fig. 3).

In group B, 12 animals ( $0.09 \%$ of all cases) were dead, which constituted $24.5 \%$ of all animals in that group shot with proven effects on their clinical status. The animals most frequently wounded during that period were again dogs $-27(55.10 \%)$, including 5 death cases, and cats $14(28.57 \%)$, but without fatalities. The other wounded animals were 3 birds (including 2 with fatal injuries), 3 hares (dead) and 2 roe deer (dead).

Statistical analysis revealed significant differences in the types of bullets, identified in the bodies of animals whose clinical status was affected by the gunshot $\left(\chi^{2}=22.7, \mathrm{P}<0.001\right)$. The animals of group A were most often shot with ball bullets, which, in contact with the body, either become deformed and disintegrate (Fig. 4a) or do not demonstrate any deformation (full metal jacket 


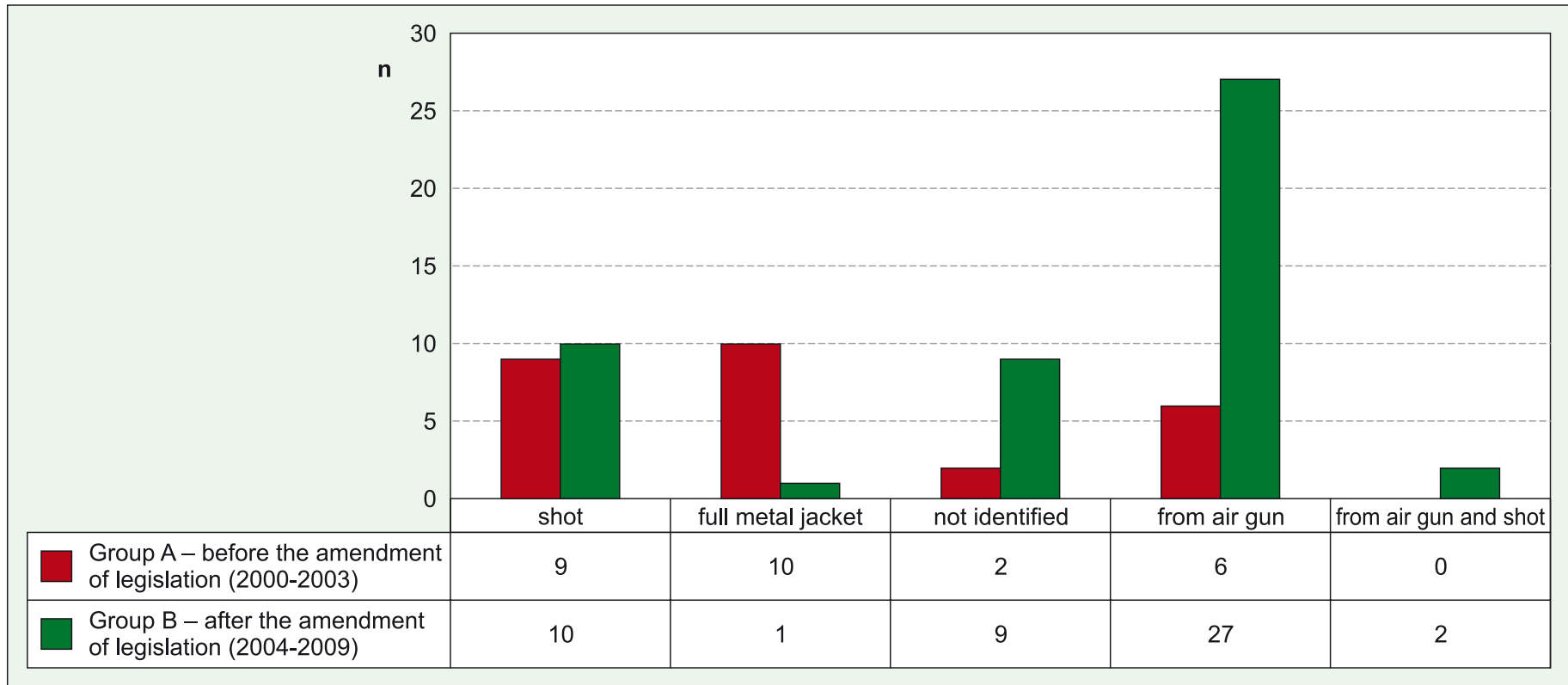

Fig. 2. Types of bullets found in the bodies of animals whose clinical status was affected by the gunshot

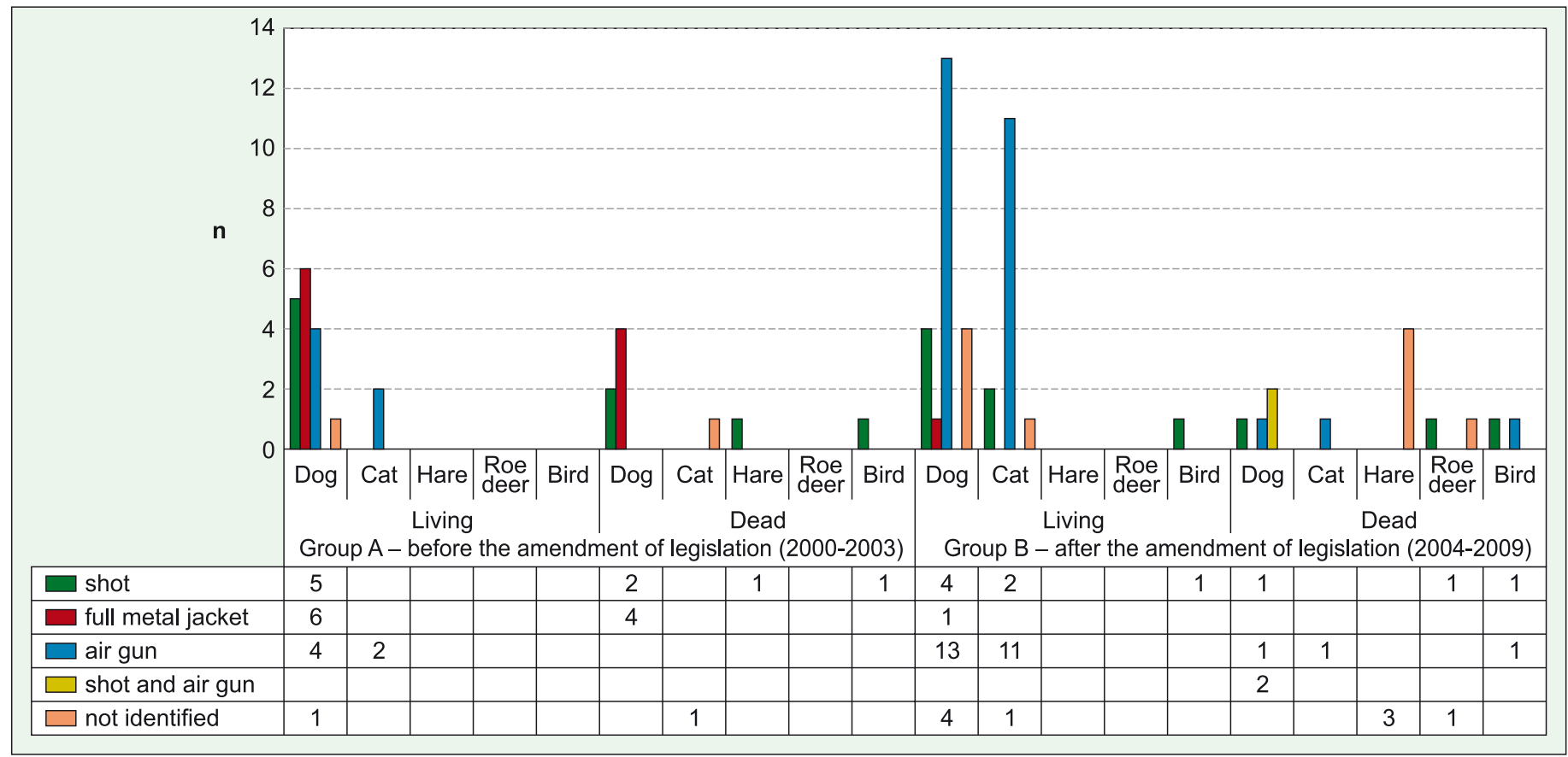

Fig. 3. Correlations between bullet types and gunshot effects on the clinical status of animals $(\mathrm{l}-$ live, $\mathrm{d}$ - dead) in two groups and time periods (A from 2000-2003, B from 2004-2009), $n$ - number of animals

bullets) $(9,20)$. There were $10(37.04 \%)$ shots of this type, exclusively in dogs. Next, there were $9(33.3 \%)$ shotgun bullets with many fine and round pellets, rarely susceptible to mechanical deformation (Fig. 4b) $(9,20)$. Airgun bullets (Fig. $4 \mathrm{c}, \mathrm{d})$ were found in $6(22.22 \%)$ animals (20). In the case of the group B animals with proven gunshot effects on their clinical status, airgun bullets were identified most frequently - in $27(55.10 \%)$ animals. In $10(20.41 \%)$ animals, only airgun pellets were found, whereas in two $(4.08 \%)$, there were both airgun pellets and a bullet from an airgun. A ball bullet was identified in one dog only $(2.04 \%)$.

In 2 animals of group A (7.41\%) and in $9(18.37 \%)$ of group B, radiographic examinations demonstrated only the presence of small metallic chips, which would indicate a perforating bullet wound, but it was impossible to determine the type of the bullet.

The history obtained from the owners of affected dogs and cats demonstrated significant differences in their awareness of gunshot injuries in their pets. Only $35.2 \%$ of cat owners suspected that a gunshot may have caused the health problems of their pets. In contrast, as many as $71.43 \%$ of dog owners were aware of gunshot injuries sustained by their pets.

Our earlier observations demonstrated that in 55.6\% of animals gunshot injuries had not been associated with any serious health problems. The animals could have been shot from several weeks to several years before 

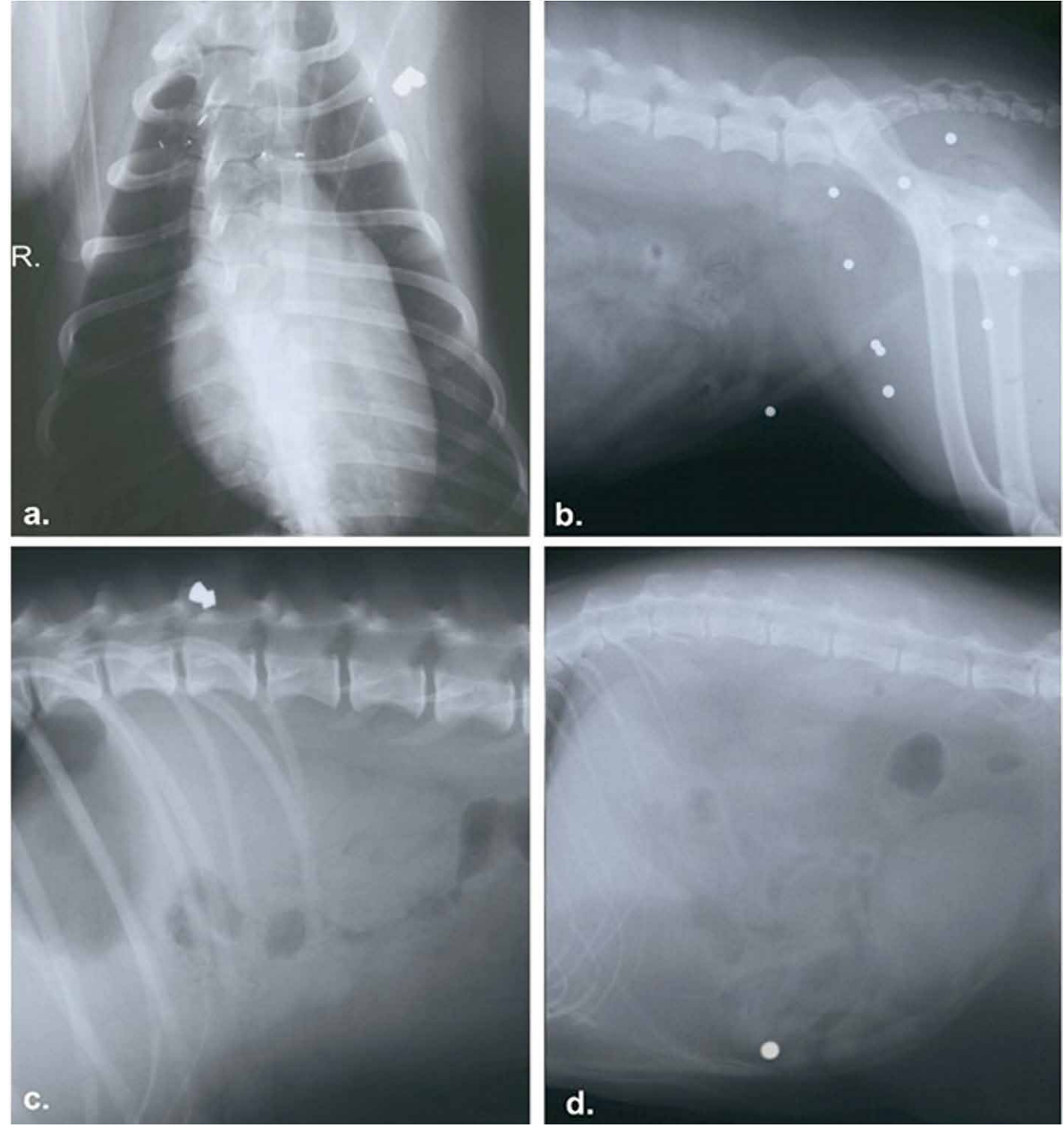

Fig. 4. Radiological pictures of bullets found in the animals examined: a. deformed full metal jacket bullet, b. shot bullets, c. d. air gun bullets

being examined. This fact suggests that the numbers of shootings reported by the authors were underestimated. It may then be supposed that the studies did not include animals which dropped dead immediately after being shot and were not presented for judicial-veterinary examination, as well as animals in which no radiological examination was performed. Nevertheless, on the basis of the data obtained, one may estimate the degree of exposure of the animal population to gunshots from various types of firearms.

Compared with human medicine, cumulative assessments of gunshot injuries in animals are very rarely presented and discussed in veterinary literature. Moreover, a comparison of our results with those obtained by other authors is somewhat impeded by significant differences in the classification of studied groups. Reports found in veterinary literature usually focus on the causes of death $(16,22,27)$. This results from the fact that a bullet, although a blunt-edged object, is a rather untypical tool that may inflict various injuries $(10,18)$. On the other hand, studies of gunshot wounds in people are carried out with regard to the whole population or to selected social groups $(5,6,21,25,28,29,31)$. Keep (13) carried out an analysis of animals, similar to that presented in this study. He found bullets in $1.7 \%$ of animals admitted to the Sydney University Veterinary Hospital for radiographic examinations. The majority of those animals had been shot with air guns, which, as the author observes, are easily available to children in Australia and are not considered dangerous. Studies by Kalinowski and Czerska (12), performed on human subjects in 2006, demonstrated that gunshots caused injury in $0.1 \%$ of patients examined at the Military Hospital in Dęblin (Lublin Voivodeship). In our studies, gunshot wounds were detected in $0.8 \%$ of patients admitted for radiological evaluation, whereas gunshot wounds with confirmed effects on the clinical status were found in $0.36 \%$ of animals. Thus, the incidence of animal shootings in Lublin Voivodeship was half as high as that reported by Keep (13) from Australia, but several times as high as the incidence of gunshot injuries to humans. The evaluation of the incidence of gunshot injuries among humans over the years is discussed in many studies, both Polish and foreign $(5-7,14,31)$. It is assumed that two factors are responsible for the growing number of gunshot injuries, the first one being the availability of firearms. Trela et al. (28) demonstrated a 14-fold increase in the number of offences with the use of firearms during the last five years of the $20^{\text {th }}$ century. The authors assume that it was the increased availability of firearms following the political transformation in Poland that was responsible for this negative development. Also studies by Bangalore and Messerli (4) confirm a positive correlation between the number of firearms per one inhabitant of the United States and the number of gun deaths. An analysis by Desmarchelier et al. (8) of the shootings of predatory birds in Quebec in 1986-2007 shows a notable decrease from $13.4 \%$ to $2.2 \%$. The author explains this trend, among others, by the decreasing number of firearms in areas inhabited by predatory birds. Another factor, which may affect the number of shootings, is the compliance with the law. Studies by Kozlowski and Michalski (15) have demonstrated a decrease in the number of deaths from violence during periods of particularly restrictive law.

The results of our studies demonstrated that the amendment of legal regulations did not affect the percentage of gunshot animals with proven effects of the gunshot on their clinical status $(0.37 \%$ during period $\mathrm{A}$ and $0.35 \%$ during period $\mathrm{B}$ ). However, there was a higher percentage of animals shot to death before the amendment. There were also differences between these two time periods in the type of bullets identified in animals whose clinical status had been affected by the gunshot. The amendment of the Act of May 21, 1999, on Firearms and Ammunition (11) opened free 
access to air guns without permit required. This weapon is cheap and easy in operation. The amendment may also be the cause of the growing incidence of gunshot wounds from low-energy weapons $(6,7)$. At the same time, air gun shootings, which usually cause little harm to the animal's body, may explain why so many animal owners were unaware of the injuries suffered by their pets. Sometimes, pet owners learn about the presence of bullets in their animals only by accident - for example, when the animals are examined radiologically (17).

Dogs constitute two thirds of gunshot animals. The most common companions of man are his easiest victims. Both dogs and cats, the latter ranking the second in the incidence of gunshot injuries, were rarely wounded or killed for protection of people or other animals. Dogs in both groups were shot with various types of weapons, while cats were most often the target of pneumatic (air gun) shooting. This fact, combined with an almost two-fold increase in the percentage of air gun shootings after the law amendment and the proven increase in the percentage of gunshot cats with confirmed effects on their clinical status recorded during the same period, may suggest that cats were shot for ill-conceived entertainment. A similar phenomenon of animal abuse has been described by other authors as well $(1,13)$. It should also be emphasised here that only one third of cat owners associated health deterioration in their pets with a possibility of a gunshot. It may also indicate that cats often remained unattended by their owners. On the other hand, dog owners' awareness of gunshot wounds in their pets was much higher.

The variable percentage of gunshot injuries in animals demonstrated in our studies in particular years has also been reported for men. This fact has not yet found any reliable explanation $(3,5,25)$ and requires further studies.

Unlike other authors, we did not find and relationship between gunshot injuries in various groups of animals and the season of the year. According to Desmarchelier et al. (8), shootings of predatory birds were usually recorded in autumn. In humans, as well, the highest number of gunshot victims is recorded in autumn months (5) or in early winter (25).

The study did not demonstrate any significant correlation between the percentage of animals gunshot with confirmed consequences for their clinical status and the law amendment concerning the availability of fire arms. On the other hand, the analysis did reveal a lower percentage of shootings with fatal consequences and a change in the type of bullets.

Such studies make it possible to indirectly estimate fire arms possessed illegally by the population in a specific area and the theoretical exposure of humans to their criminal use. The potential threat from fire arms may also be compared between different parts of the country. It is particularly important for regions such as Lublin Voivodeship, where the criminal use of fire arms is very rare, and where data on this type of threats, originating from few cases, are relatively selective and inaccurate.

\section{References}

1. Arluke A.: Animal Abuse as Dirty Play. Symbolic Interaction 2002, 25, 405-430. 2. Asamura H., Takayanagi K., Chunynan L., Ota M., Fukushima H.: The judgement of a gunshot wound with severe post-mortem changes. Legal. Med. 1999, 1, 185$-187$

3. Azmak D., Altun G., Bilgi S., Yilmaz A.: Firearm fatalities in Edirne, 1984-1997. Forensic Sci. Int. http://www.ncbi.nlm.nih.gov/pubmed/98003581998, 95, 231$-239$

4. Bangalore S., Messerli F. H.: Gun Ownership and Firearm-related Deaths. Am. J. Med. 2013, 126, 873-876.

5. Bloch-Bogusławska E., Engelgardt P., Paradowska A.: Obrażenia postrzałowe w materiałach Katedry i Zakładu Medycyny Sądowej Cm UMK w Bydgoszczy z lat 1995-2005. Arch. Med. Sąd. Krym. 2007, 57, 313-317.

6. Boström L., Nilsson B.: A review of serious injury and death from gunshot wounds in Sweden 1987 to 1994. Eur. J. Surg. 1999, 165, 930-936.

7. Burg A., Nachum G., Salai M., Haviv B., Heller S., Velkes S., Dudkiewicz I. Treating civilian gunshot wounds to the extremities in a level 1 trauma center: Our experience and recommendations. IMAJ 2009, 11, 546-551.

8. Desmarchelier M., Santamaria-Bouvier A., Fitgerald G., Lair S.: Mortality and morbidity associated with gunshot in raptorial birds from the province of Quebec: 1986 to 2007. CVJ 2010, 51, 70-74.

9. Hollerman J. J., Fackler M. L., Coldwell D. M., Ben-Menachem Y.: Gunshot wounds: 2. Radiology. AJR 1990, 155, 691-702.

10. Jakliński A., Kobiela J., Jaegermann K., Marek Z., Tomaszewska Z.: Medycyna sądowa. PZWL, Warszawa 1972, p. 144.

11. Journal of Laws of 2004, No. 52, item 525 (Ustawa z dnia 21 maja 1999 r. O broni i amunicji. Dz. U. 2004, Nr 52 poz. 525.)

12. Kalinowski P., Czerska B.: Epidemiology of trauma among hospitalized in 2006 in The 6. Military Hospital in Deblin. Probl. Hig. Epidemiol. 2007, 88, 455-460.

13. Keep J. M.: Gunshot injuries to urban dogs and cats. Austr. Vet. J. 1970, 46, 330$-334$

14. Kopras A., Liebert W., Moskal J.: Terminal ballistics of firearms gunshots head injuries. Neuroskop 2008, 10, 23-30

15. Kozlowski J., Michalski M.: An analysis of violent deaths in the period of more intense abidance of the criminal law from a point of view of forensic medicine and criminology. Medical News 2006, 75, 162-167.

16. Listos P., Gryzinska M., Kowalczyk M.: Analysis of cases of forensic veterinary opinions produced in a research and teaching unit. J. Forensic Leg. Med. 2015, 36, 84-89.

17. Łojszczyk-Szczepaniak A., Brodzki A., Żylińska B.: Ciało obce w pęcherzu moczowym psa - radiologiczny obraz przypadku. Mag. Wet. 2012, 21, 230-234.

18. Michalski Z.: Weterynaria sądowa. Wydawnictwo Akademii Rolniczej, Wrocław 1993, 77.

19. Miller P., Pearn J., Marcollo S.: Radiology in Rwanda. Australasian Radiology 1995, 39, 337-342.

20. Morgan J. P., Wolvekamp P.: Atlas of Radiology of the Traumatized Dog and Cat Schlütersche, Hannover 2004, 492-522.

21. Newgard C. D., Kuppermann N., Holmes J. F., Haukoos J. S., Wetzel B., Hsia R. Y., Wang N. E., Bulger E. M., Staudenmayer K., Mann N. C., Barton E. D., Wintemute $G$.: Gunshot injuries in children served by emergency services. Pediatrics 2013, 132, 862-870.

22. Przystasz T., Krupa J., Stanowski E.: Penetrating gun shot wound of the chest. Medical News 2004, 73, 97-100.

23. Rainio J., Lalu K., Penttilä A.: Independent forensic autopsies in an armed conflict: investigation of the victims from Racak, Kosovo. Forensic Sci. Int. 2001, 116, 171-185.

24. Sansom J., Labruyere J.: Penetrating ocular gunshot injury in a Labrador Retriever Vet. Ophthalmology 2012, 15, 115-122.

25. Solarino B., Nicoletti E. M., Di Vella G.: Fatal firearm wounds: A retrospective study in Bari (Italy) between 1988 and 2003. Forensic Sci. Int.http://www.ncbi. nlm.nih.gov/pubmed/9800358 2007, 168, 95-101.

26. Szponder T.: Złamania postrzałowe kości długich u małych zwierząt. Mag. Wet. 2002, 11, 36-37.

27. Thali M. J., Kneubuehl B. P., Bolliger S. A., Koenigsdorfer A. C., Ozdoba C., Spielvogel E., Dirnhofer R.: Forensic veterinary radiology: Ballistic-radiological 3D computer tomogrphic reconstruction of an illegal lynx shooting in Switzerland. Forensic Sci. Int. 2007, 171, 63-66.

28. Trela F., Kunz J., Bolechała F., Kowalski P., Moskała A., Rajtar R.: Crimes against life in the material of Cracow's Forensic Medicine Institute - comparative analysis in the years 1986-1990 and 1996-2000. Archiv Forensic Med. Criminol. 2002, 52, 1-6

29. Vassar M. J., Kizer K. W.: Hospitalizations for firearm-related injuries. A population-based study of 9562 patients. JAMA 1999, 275, 1734-1739.

30. Volk S. W., Bohling M. W.: Comparative wound healing - Are the small animal veterinarian's clinical patients an improved translational model for human wound healing research? Wound Repair Regen 2013, 21, 372-381.

31. Witkowski Z., Lasek J., Kopiszko K., Stasiak M.: Obrażenia ciała w następstwie postrzałów - aspekty epidemiologiczne i kliniczne. Wiad. Lek. 2006, 5-6, 341-345.

Corresponding author: Piotr Listos, PhD. Department of Pathological Anatomy, University of Life Sciences, Głęboka 30, 20-033 Lublin, Poland; e-mail: piotr.listos@up.lublin.pl 